\title{
FRONTIERS
}

\section{Do the Maths}

\author{
Lê Dũng Tráng
}

Developing countries have historically excelled in mathematics, nourishing deeply rooted traditions of knowledge.

W hy should developing countries invest in mathematics? Should not more pressing, critical social and economic needs take precedence over efforts to build capacity in a field that is apparently dedicated to abstract musings?

Such views of mathematics are misguided on many accounts. Mathematics plays a fundamental role in, for example, electronic communications, environmental assessments and modelling, biotechnology and genetics, and the development of new materials. This assumption, moreover, has been disproved by the actions taken by the developing countries themselves.

Over the past several decades, numerous developing countries have gained international standing in mathematics. India's Tata Institute of Fundamental Research, founded in 1945 in Mumbai, has been home to some of the world's pre-eminent mathematicians, including K. Chandrasekharan, M. S. Narasimhan and C. S. Sheshadri. In the late 1950 s and early 1960s, Argentina developed a strong international presence in mathematics marked by the contributions of such institutions as the National Research Council (CONICET) and the University of Buenos Aires School of Sciences, and such individuals as Cora Ratto de Sadosky, Alberto González Domínguez and Luis Santaló.

More recently, other developing countries have emerged as vibrant centres of mathematical research and training, with faculty and students competing successfully on the world stage. These include Brazil (in dynamical systems), China (in differential geometry), India (in combinatory mathematics), Mexico (in geometry and analysis) and Vietnam (in convex analysis).

Each of these countries has accepted the notion that a strong national capacity in mathematics is a key to promoting both science and science-based development. Equally importantly, these countries have concluded that domestic competency in mathematics has an important bearing on the overall quality of a nation's educational base, from economics to engineering and from medicine to sociology.

Yet, beyond the specific fields in which mathematics serves as an invaluable tool of insight and understanding, there is a cultural dimension to its study that helps to shape, and reshape, thinking. As Galileo Galilei noted, "The book of nature lies open for all to read, and it is written in the language of mathematics." Indeed, the language of mathematics complements the language of

Lê Dũng Tráng (TWAS Fellow 1993) heads the Mathematics Group at the Abdus Salam International Centre for Theoretical Physics (ICTP) in Trieste, Italy. humanities. All fields of mathematics focus on clear and concise symbolic logic, whereas the humanities are more concerned with the emotive power of experience and the written word.

Both mathematics and the humanities seek the truth, although from different perspectives, and embody fundamental principles that are closely allied with ethical standards of behaviour. Mathematics provides a bridge between science and the humanities. Thus, it should come as no surprise to learn that, from the 1800s until the early twentieth century, mathematicians were known as natural philosophers.

The value of mathematics - as a language, tool and philosophy - has encouraged developing countries to invest in mathematical institutions and support individual mathematicians. The most tangible aspects of national competency in mathematics reside in greater understanding of advanced technologies, which increasingly depend more on fundamental knowledge of mathematics and the basic sciences than on capital investment.

It also helps that receiving training in mathematics is more affordable for students than in comparable fields, such as physics and engineering. It requires little more than a pencil and a notebook or a piece of chalk and a chalkboard. The quality of the thought, not of the equipment, determines the quality of the output.

India's growing progress in information technology owes much to the mathematical know-how of its knowledge workers. China's contributions to space science and biotechnology are likewise due, in part, to the mathematical skills of its researchers. China now has more than 8,000 graduates with doctorates in mathematics.
Brazil's Instituto de Matematica Pura e Aplicada (IMPA), created in 1952, is now recognized as one of the world's pre-eminent mathematical centres. Mexico has established five advanced mathematical centres over the past three decades. Vietnam's investment in mathematics has made its students into the top performers in the mathematical Olympiads.

Many other developing countries have participated in the 'blossoming' of mathematics in the South. Yet, such efforts, if they are to be sustained, will depend on the ability to train and retain quality teachers, as well as on continuing political stability.

The rising interest in mathematics among developing countries reflects their economic aspirations, and follows the same policy path that accounts for mounting investments in a range of scientific and technological fields. Governments across the South are increasingly viewing mathematics as an instrument for poverty alleviation and sustainable development.

At the same time, I fervently hope that the deeply cultural dimensions of mathematics, which are an equally important part of human intellectual history as the world's artistic and literary heritage, will not be compromised. I know that non-mathematicians might find it odd to compare the Poincaré Conjecture to the Mona Lisa. Yet, mathematics is as contemplative, aesthetic and elegant as any other creative pursuit.

Let mathematics help developing countries to gain greater material well-being. But also let mathematics shed light on the wonders of nature, and bring rays of logic and precision to the mysteries of our world.

\section{VIEWPOINT I Berit Olsson Research is no luxury}

Research is not a luxury that is reserved only for richer countries. Poorer ones need to build a critical mass of researchers too, and to develop their own research communities that prove to be sustainable over time. Action, of course, is needed to tackle many issues in the developing countries, but it must be based on knowledge - and knowledge generated within these countries. Too often, research has been exclusively associated with new and innovative products and services. While that is important, it is not the entire story. Researchers serve as knowledge mediators in our knowledge-based globalized world. They play an instrumental role in acquiring, analysing and disseminating the complex data and information that drive today's global economy. They are a bridge to the world beyond a nation's borders. They offer expert advice to government. They act as a primary source of critical thinking for nations, and they provide the foundation for evidence-based decision-making in such critical fields as agriculture, energy and public health. 